\title{
PROGRAM ANALYSIS AND PLANS PLUTONIUM UTILIZATION PROGRAM FY-1967 THROUGH -1970
}

RESEARCH and

\section{DEVELOPMENT} REPORT 


\section{LEGAL NOTICE}

This report was prepared as an account of Government sponsored work. Neither the United States, nor the Commission, nor any person acting on behalf of the Commission:

A. Makes ony warranty or representation, expressed or implied, with respect to the accuracy, completeness, or usefulness of the information contained in this report, or that the use of any information, apparatus, method, or process disclosed in this report may not infringe privately owned rights; or

B. Assumes any liabilities with respect to the use of, or for damages resulting from the use of any information, apparatus, method, or process disclosed in this report.

As used in the above, "person acting on behalf of the Commission" includes any employee or contractor of the Commission, or employee of such contractor, to the extent that such employee or con. tractor of the Commission, or employee of such contractor prepores, disseminates, or provides access to, any information pursuant to his employment or contract with the Commission, or his employment with such contractor.

\section{PACIFIC NORTHWEST LABORATORY \\ RICHLAND, WASHINGTON \\ operated by \\ BATTELLE MEMORIAL INSTITUTE}

for the

UNITED STATES ATOMIC ENERGY COMMISSION UNDER CONTRACT AT(45-1)-1830 


\title{
33679000602849
}

\author{
BNWL - 298 \\ UC-80, Reactor Technology
}

\author{
PROGRAM ANALYSIS AND PLANS \\ PLUTONIUM UTILIZATION PROGRAM \\ FY-1967 Through - 1970 \\ Compiled By \\ F. G. Dawson, Program Leader
}

Principal Contributors

F. G. Dawson

D. R. de Halas

E.A. Eschbach

H. Harty

W. D. Richmond

M. T. Walling

$$
\text { July, } 1966
$$

PACIFIC NORTHWEST LABORATORY

RICHLAND, WASHINGTON 


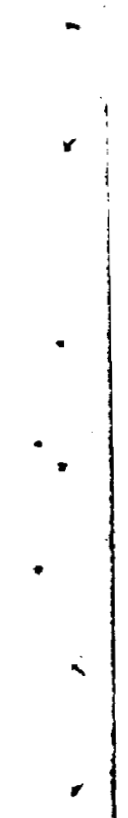


Printed in USA. Price $\$ 2.00$. Available from the Clearinghouse for Federal Scientific and Technical Information National Bureau of Standards

$\mathrm{U}$. S. Department of Commerce Springfield, Virginia 


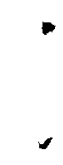

.

. 
INTRODUCTION

MAJOR PROGRAM ACCOMPLISHMENTS

Plutonium Value

Cost Premium for Plutonium Fuel.

Safe Handling of Large Quantities of Plutonium.

Packed-Particle Fuels

Pneumatic Impaction of Fuel Materials.

Cross Section Measurements

Reactor Physics Analysis Methods

Experimental Physics Data.

Physics Predictions for Plutonium-Fueled Reactors.

PRTR Operation with Plutonium Fuel.

PRTR Moderator Design Features

Zirconium Pressure Tube Technology.

Spent Fuel Reprocessing

Plutonium Ceramics Program

PROGRAM PLANS.

Overal1 Program Needs

Physics Program.

Light Water Lattice Physics Data

Irradiation Experiments

PRTR Batch Core Experiment

EBWR Demonstration and Saxton Experiment.

Fue1 Heterogeneity Effects on Reactivity.

Fuel Fabrication Studies.

Incremental Cost Evaluation.

Radiation Problems with High Exposure Plutonium

Advanced Plutonium Fuel Development

Particle Agglomeration Process

Demonstration of Fuel Performance

PRTR Batch Core Experiment

FERTF Irradiations

Fuel Rupture Consequences.

EBWR Demonstration and Associated Studies

Reactor Decontamination

Optimization of Reactor and Core Designs for Plutonium Recycle

Industrial Assistance.

PROGRAM RED SCHEDULE

Task Descriptions 


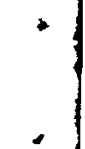

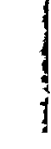

-

.

. 


\author{
PROGRAM ANALYSIS AND PLANS \\ PLUTONIUM UTILIZATION PROGRAM \\ FY-1967 THROUGH -1970
}

\section{IN TRODUCT ION}

The Hanford Plutonium Utilization Program (PUP) was established by the AEC in September 1956 at the Hanford Laboratories of the General Electric Company. In January 1965, BattelleNorthwest assumed responsibility for the program concurrently with assumption of the operating contract for the Hanford Laboratories. The mission of the program has been to develop base technology to support the commercial application of plutonium recycle in thermal reactors. With the end of government buy-back of plutonium in 1971, and with plutonium valued at hundreds of millions of dollars expected to be produced from power reactors by the early 1970's, commercial application of plutonium recycle may be regarded as inevitable by that time.

This timing of commercial application requires that the $A E C-B$ attelle program be largely completed by 1970 , and this will be the case. Work of major importance to program objectives has been accomplished already, and major segments of the program are in progress or about to start which will be completed by 1970 . The operation of the Plutonium Recycle Test Reactor (PRTR) on the PUP will be completed in early FY-1969. This report reviews these program accomplishments and the plans for future work to properly complete the program.

The realization of these plans is, of course, dependent on continued support by the Atomic Energy Commission. It is also subject to the usual uncertainties of Research and Development results of the future and to modifications arising from integrated planning with industry of Research and Development required to support industrial application. Discussions have been held with the Edison Electric Institute and with reactor manufacturers in this regard, and others will be conducted in the future.

The scope of the Hanford program has been broad, including plutonium fuels development, chemical reprocessing studies, physics of plutonium-fueled reactor systems, technical and economic optimization studies of plutonium fueled reactors and plutonium fuel cycles, and other $R E D$ and services required to support the primary purposes of the program. Principal facilities of the program include the Plutonium Recycle Test Reactor (PRTR), the Plutonium Recycle Critical Facility (PRCF), and the Plutonium Fuels Laboratory. 
,

י 
In cooperation with Argonne $\mathrm{Na}$ tiona 1 Laboratory, the EBWR is being used to extend the range of irradiation experience to the boiling 1 ight water environment. A similar program for pressurized light water systems is being conducted in the Saxton Reactor by Westinghouse Corporation under contract to the AEC.

\section{MAJOR PROGRAM ACCOMPLISHMENTS}

Some of the major accomplishments of the Plutonium Utilization Program are briefly described below.

\section{Plutonium value}

Determination of the value of plutonium as fuel in thermal reactors has been of major importance in establishing the economics of plutonium recycle and has led to the establishment of the current AEC buy-back price for Pu. The value of fissile plutonium was found to be proportional to the price of fully enriched uranium and is currently in the range of $\$ 8$ to $\$ 11$ per gram for uniform dispersions of $\mathrm{PuO}_{2}$ in $U_{2}$ rods. These uniform dispersions are the simplest to implement and thus have enjoyed a priority. For many applications plutonium may prove to be more valuable in other fuel configurations such as one involving lumped Pu, the "pencil" configuration.

Cost Premium for Plutonium Fuel

It has been established that fabrication costs for rod geometry $\mathrm{UO}_{2}-$ $\mathrm{PuO}_{2}$ fuels are on 1 y about $20 \%$ more than for equivalent $\mathrm{UO}_{2}$ fuels, when produced at large throughput rates. There is potential for even further reduction in this incremental cost.
This $20 \%$ figure is in contrast to early estimates of cost penalties of several hundred percent. Although fabrication with the more radioactive, high exposure plutonium is yet to be demonstrated, enough information on radioactivity levels is available to indicate that the incremental fabrication costs will only be slightly higher than for low exposure plutonium and will not be a deterrent to the utilization of plutonium fuels.

\section{Safe Handling of Large Quantities of} plutonium

Before the advent of the Plutonium Utilization Program there was essentially no experience in producing plutonium-bearing fuel elements. Safe and efficient methods for processing large quantities of plutonium have been developed during the past eight years and about $35 \mathrm{kilograms}$ of plutonium have been fabricated into fuel elements. There has not been a serious accident to personnel during this eight-year peiod.

\section{Packed-Particle Fuels}

Development of the swaging and vibrational compaction processes for production of "packed-particle" fuel rods represents a significant contribution to nuclear fuel fabrication technology. The techniques employed in fabricating packed-particle fuel rods, because they are versatile, have been adapted in varying degrees by most of the major fuel fabricators in the U.S. and abroad. The packedparticle fuel has been largely proved through extensive irradiation tests in the MTR, ETR, and PRTR. More 


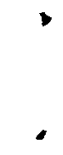


than 2400 rods have been irradiated in the PRTR, another 1500 rods have been fabricated for EBWR irradiations, and about 150 rods are in the Saxton Reactor.

Pneumatic Impaction of Fuel Materials

A major problem in the development of mixed oxide fuels was to provide high density fuel particles with good plutonium distribution for the vibrational compaction process. The pneumatic impaction process for densifying fuel was developed and proved to be a satisfactory solution. This process may be cheaper than the fusion process, which is limited in batch size by criticality considerations, or the sintering process, which involves more handling of the material. Pneumatic impaction provides a means of consolidating uniform mixtures of fine powders of $\mathrm{UO}_{2}$ and $\mathrm{PuO}_{2}$ so as to maintain a uniform distribution of the two materials during subsequent processing. This feature is of importance in fabricating both thermal reactor recycle fuels and fast reactor fuels.

\section{Cross Section Measurements}

Thermal neutron cross-section measurements on uranium and plutonium isotopes have provided a firm basis for analyzing and predicting the therma 1 neutron spectrum in uranium and plutonium fueled reactors. A study of tota 1 cross-section measurements for neutrons in the range of 3 to 15 Mev was made for more than 50 elements. For over half of these measurements, the results constitute the only data a:railable. Measurements on important fast reactor materials: iron, sodium, and potassium were also made.
Measurements on the scattering law for $\mathrm{H}_{2} \mathrm{O}$ include a range of parameters and high temperature. Considerable effort is being expended on interpretation and development of thermalization models usable in reactor physics analysis.

\section{Reactor Physics Analysis Methods}

A comprehensive system of reactor physics and fuel cycle analysis methods that specifically accounts for the complex nature of the nuclear properties of the plutonium isotopes has been developed and adapted to the computer. In some instances, this required new developments; in olners, standard computer codes used in industry for uranium systems were modified for analysis of plutonium systems. The codes were required in performing theory-experiment correlations and studies on plutonium utilization and fuel cycle analyses. They are being exported extensively to industry and other laboratory organizations to be used in their plutonium utilization studies. The majority of the codes are independent of the type of computer and are therefore of general use throughout the industry.

\section{Experimental Physics Data}

A wealth of experimental physics data has been accumulated for plutonium systems. This was needed in order to provide a backlog of data which can be utilized to check the calculational techniques for plutonium-fueld reactor designs. Some data are available on graphite and heavy water systems. However, since light water moderated reactors (BWR's and PWR's) are further advanced in their development 


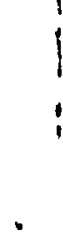

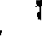

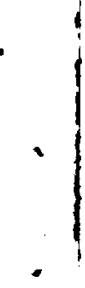
, , 
than other reactor types, and therefore more likely to be the initial users of plutonium, particular attention is being given to these types. The completed and current programs provide data over a range of plutonium fuel compositions and moderator-tofuel ratios typical of both boiling and pressurized water reactors. These data are being used in a systematic manner in evaluating calculational techniques developed in the laboratory.

The data are similarly being used by others; e.g., they were used extensively by the Argonne National Laboratory in the pre-analyses of the plutonium experiment in the EBWR and by westinghouse in designing the Saxton plutonium experiments.

Physics Predictions for PlutoniumFueled Reactors

A systematic evaluation using experimental results is being made of the theoretical physics models and computational techniques developed for predicting and analyzing the neutronic characteristics of plutoniumfueled reactors. Predictions as to criticality and fuel exposure-reactivity relationships of plutoniumfueled lattices can now be made with the same accuracies that were possible for $\mathrm{UO}_{2}$ fuel lattices when the first large commercial boiling water and pressurized water reactors were designed. With the completion of the clean lattice experiments now under way, the plutonium fuel burnup and critical experiments being conducted in the EBWR during FY-1966-1968 and in the PRTR during FY-1966-1969, and the operation of Saxton with pluto- nium fuel (FY-1966-1968), it should be possible to approach the level of accuracies currently existing for U-235 enriched boiling water and pressurized water power reactors.

PRTR 0peration with Plutonium Fuel

Operation of the PRTR with plutonium bearing fuel has revealed no unexpected physics characteristics. The PRTR has logged over 4l,600 MWd's (since early 1961) with plutonium fue 1 loadings.

\section{PRTR Moderator Design Features}

Control of a reactor through regulation of the moderator level by a gas balance system was employed for the first time in the PRTR. This control system eliminates the need for strong control rods, thereby permitting more constant power distribution in the reactor during operation. The use of the gas balance system also permitted the design of a novel shutdown systam in which gas pressure can be very rapidly equalized to "dump" the moderator and scram the reactor. Together with the moderator dump for shutdown, the gas balance system is the most successful novel design feature of the PRTR.

Zirconium Pressure Tube Technology

The PRTR is the first reactor in the U.S. to employ (zirconium) pressure tube construction in a high pressure system. In supporting and proving out this design, the base technology was developed with applicability far beyond immediate PRTR objectives. Technology and experience were made available to guide pressure tube power reactor concepts such as 
2

- 1 
the HWOCR. Fabrication and inspection technology of zirconium alloy pressure tubing were developed to a degree that industrial suppliers can meet the stringent quality and size requirements for reactor tubing. Substantial contributions were made to the basic understanding of the corrosion, hydriding, and mechanical properties of zirconium alloys.

\section{Spent Fuel Reprocessing}

Spent fuel reprocessing Research and Development has had two objectives: (1) to provide capability for processing PRTR fuels in Hanford reprocessing facilities, and (2) to develop new processes of potential economic advantage for plutonium-bearing fuels.

The "Zirflex Process," developed in part under PUP, is a stainless-steel compatible dissolution process for zirconium. It was developed and engineered through pilot plant demonstration and successfully used in the Redox plant on a $1400 \mathrm{~kg}$ batch of irradiated PRTR, $\mathrm{UO}_{2}-\mathrm{PuO}_{2}$ fuel elements. The process is planned for use in the Hanford Purex plant for Zircaloy clad fuel elements and also for use in other domestic and foreign plants.

Research and Development resulted in an anion exchange process for recovery of plutonium from plutoniumenriched fuel elements, and amine-extraction process for the same purpose, the Salt Cycle Process for re-enrichment and partial decontamination of $\mathrm{UO}_{2}-\mathrm{PuO}_{2}$ fuel material by electrodeposition, the direct calcination of plutonium nitrate, and miscellaneous other processes. With the exception of the Salt Cycle Process, all processes were demonstrated on a bench scale.
Essentially all elements of the Salt Cycle Process; decladding, dissolution, electrodeposition, and precipitation were tested on a several kilogram scale. This program culminated in a demonstration in which about twenty kilograms of $\mathrm{UO}_{2}-2 \% \mathrm{PuO}_{2}$ were prepared from irradiated PRTR oxide fuel material, used in the remote refabrication of fuel elements, and reirradiated in the PRTR.

Significant fundamental knowledge of the nature of molten salt systems was gained.

Plutonium Ceramics Program

This program was a part of the Plutonium Utilization Program through FY-1965. It supplied a wealth of basic data on physical and thermal properties, basic irradiation behavior, compatibilities, and phase relationships on plutonium compounds. These data are of interest to both plutonium-fueled thermal and fast reactors. The facilities and techniques for measuring high temperature properties of plutonium acquired under this program are probably the most complete in the U.S.

\section{PROGRAM PLANS}

Overal1 Program Needs

In spite of the accomplishments to date* there is much work to do before

*A comprehensive review of the status of plutonium recycle technology was presented to invited representatives of U.S. industry on April 3-4, 1964 , in Richland, washington. Reported in HW-82400, "Proceedings Commercial Fabrication of Plutonium Fuels, "July 1964. Additional accomplishments were reported at an international 
1 
the technical and economic feasibility of plutonium recycle in the light water reactors is established. Part of these needs can best be carried out by the Plutonium Utilization Program at

Battelle-Northwest, but the demonstration of plutonium recycle in commercial reactors must be carried out by private industry.

The remainder of the Plutonium Utilization Program is focused on obtaining the data required to assure early commercial application. The physics program will be continued until criticality and fuel-exposure relationships can be predicted with sufficient accuracy to permit reliable reactor calculations to be made and accurate fuel cycle costs to be predicted. Further data are also required to refine reactor safety analyses. High exposure plutonium (containing the $\mathrm{Pu}-236,238$, and 240 isotopes) from power reactor operation will be used in fabrication studies and dose rate measurements made, in order to improve estimates of the incremental costs associated with plutonium fuel element fabrication. The current irradiation program is intended to determine whether plutonium-bearing fuels are limited to power densities or exposures significantly less than those attainable with enriched uranium fuels. Additional work is necessary to demonstrate that the consequences of plutonium fuel rod failure are not significantly different than for uranium

IAEA conference on the use of plutonium as a nuclear fuel hald in Vienna, Austria, in December 1964. The most recent extensive reporting was at the joint AIF-ANS-EEI "Plutonium Information Meeting" at Washington D.C. in March 1966. fuel rod failures. Cycle analyses and engineering evaluations of various means of recycling plutonium will be completed in order to identify ways of using plutonium in existing reactors without undue fuel element handing penalties.

A demonstration of all the steps in the recycle by private industry will accelerate the commercial use of plutonium recycle. Plutonium produced in commercial reactors should be separated by commercial plants as is being done by NFS. A private fuel fabricator should then be encouraged to fabricate this plutonium into fue 1 elements for reinsertion into a power reactor. The information on spentLue1 reprocessing, the demonstration of fuel element refabrication with power-reactor-produced plutonium and the successful re-irradiation of the fuel, all done in commercial facilities, will provide a significant conclusion to the program.

\section{Physics Program}

Light Water Lattice Physics Data

Considerable lattice physics data have already been accumulated on 1 ight water moderated, plutonium fuel systems. The data accumulation is not, however, completed and the evaluation has only been made over a 1 imited range of conditions. Further essential experiments are under way which should yield the necessary data for developing the required engineering physics methods for the initial recycle of plutonium in boiling and pressurized water reactors (See Tasks $\mathrm{P}-3$ and $\mathrm{P}-4$ ). Single region experiments with boron in the $\mathrm{H}_{2} \mathrm{O}$ moderator will be conducted with selected 2 wt $\mathrm{PuO}_{2}$ and 5 wt $\%$ and 2 wt: PuAl fuel 


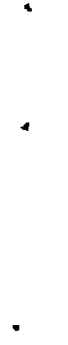

.

.

,

. 
elements to reduce the neutron leakage effect of small cores. Single region experiments in $\mathrm{H}_{2} \mathrm{O}$ moderator will be conducted with $5 \mathrm{wt} \%$ and $2 \mathrm{wt} \% \mathrm{PuAl}$ fuel elements as a check on experimental accuracy and as base measurements for the experiments containing boron in the moderator (See Task P-1). In addition, studies of loadings which have zones of fuel elements with various $\mathrm{Pu}^{240}$ concentrations and 2 wt: $\mathrm{PuO}_{2}-\mathrm{UO}_{2}$ will be conducted. Subcritical and critical experiments will continue in zero power reactors with emphasis on the effects of plutonium isotopic ratios. Loading studies of 2 wt: $\mathrm{PuO}_{2}-\mathrm{UO}_{2}$ fuel elements containing 8,16 , and $24 \mathrm{wt} \% \mathrm{Pu}^{240}$ moderated with 1 ight water are under way. This series of experiments will greatly increase the available experimental data on lattices typical of boiling and pressurized water reactors. Additional experiments will be performed on $\mathrm{Pu}-\mathrm{Al}$ and $\mathrm{PuO}_{2}-\mathrm{UO}_{2}$ fuels already fabricated. The experiments should help locate the factors which are causing major uncertainties in reactor design calculations.

\section{Irradiation Experiments}

Nondestructive and destructive analysis will continue for mixed oxide fue 1 with various concentrations of $\mathrm{PuO}_{2}$ and plutonium containing various concentrations of $\mathrm{Pu}^{240}$. In addition, the analysis of the results of $\mathrm{UO}_{2}$ and $\mathrm{Pu}-\mathrm{A} 1$ irradiations will be completed (See Task ( - 2).

\section{PRTR Batch Core Experiment}

A controlled large-scale burnup experiment is planned for the PRTR to provide information on those operating characteristics of a $\mathrm{UO}_{2}-\mathrm{PuO}_{2}$ fueled reactor which are typical of power reactor conditions, e.g., power coefficients, xenon worth, and long-term burnup effects on reactivity (See Task P-6). The experiment involves the operation of the PRTR loaded with 66 fue 1 elements containing about 2.3 tons of $\mathrm{UO}_{2}-2 \mathrm{wt} \% \mathrm{PuO}_{2}$ fuel. The central 54 elements wili be used in a series of critical experiments at various stages of fuel burnup to determine the nuclear properties of the fuel as a function of exposure. Experiments will continue to a total average core exposure of approximately $10,000 \mathrm{MWd} / \mathrm{MT}$ or a maximum element exposure of approximately $13,000 \mathrm{MWd} / \mathrm{MT}$. These exposures will be accumulated at maximum specific powers of about $54 \mathrm{~kW} / \mathrm{kg}$ of fuel where the maximum point burnup will be approximately 20,000 MWd/MT. The Batch Core Experiment will provide statistically significant irradiation data on highburnup plutonium fuels operating with maximum fuel temperatures $\left(2600-2800{ }^{\circ} \mathrm{C}\right.$ ) near melting.

Special $\mathrm{UO}_{2}-\mathrm{PuO}_{2}$ test elements will be irradiated in the centrally located Fuel Element Rupture Test Facility (FERTF) at specific powers as high as $80 \mathrm{~kW} / \mathrm{kg}$ giving significant fuel melting. These experiments will provide a source of fuel rods to study possible reactivity effects of molten fuel operation with powder and pellet fuels containing low and high exposure plutonium. The reactivity effects will be measured in the PRCF.

EBWR Demonstration and Saxton Experiment

To provide engineering-scale demonstration of the practicality of plutonium recycle in water reactors and pertinent physics design data, the AEC has 


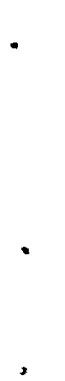


sponsored experiments with plutonium loadings in the EBWR and the Saxton reactors. The EBWR demonstration is a joint program between Argonne Laboratory and Battelle-Northwest; the Saxton experiment is being conducted by Westinghouse.

The experiment in the EBWR will include the loading of sufficient $\mathrm{PuO}_{2}$ $\mathrm{UO}_{2}$ in the center of the core ( $\sim$ onefourth loading) so that the predominant reactivity defect produced by fuel burnup will be caused by the plutonium depletion. The reactor will be operated at power, and burnup will proceed until the nuclear characteristics as a function of irradiation in the EBWR-type core are determined (See Task PRD-2). lhese characteristics are determined by:

- observations of reactor characteristics during operation at power, - physics experiments on the full reactor and the plutonium zone alone at various stages of burnup, and

- reactivity measurements and destructive analysis of the standard $\mathrm{PuO}_{2}{ }^{-}$ $\mathrm{UO}_{2}$ and special elements irradiated in the core.

An extensive set of physics experiments with the plutonium fuel is being performed in the EBWR facility before power operation begins. These experiments will establish a basis on which to measure the effects of burnup on reactivity. Then, as burnup proceeds, the reactor will be shut down at intervals for a similar set of experiments. At these intervals, standard as well as special rods from subassemblies will be removed and shipped to $B N W$ for carefully controlled reactivity measurements and destructive analysis to determine fuel composition. Al1 the data from these experiments will be correlated with reactor statistics and burnup calculational methods. Methods will be sought to minimize any dis. crepancies observed. At the completion of this integrated program, the technological basis for recycling plutonium in $1 \mathrm{ight}$ water reactors should be well established.

Preirradiation critical experiments in the EBWR began in September, 1965. Power operation should start FY-1967 and be complete by FY-1969. Postirradiation fuel examination and other terminal testing and calculations will be completed before FY-1970.

The data obtained from clcan critical experiments and the burnup of fuel in the Saxton reactor will be used in our evaluations and will complement the data from the EBWR in that the plutonium enrichment level is higher and one reactor is a BWR and one a PWR.

Fuel Heterogeneity Effects on Reactivity

Therc may be cost incentives to using mixed oxide fuel produced by mechanical blending rather than coprecipitation. However, the cost of mechanical blending increases as the specified degree of homogeneity is increased. There also appears to be considerable incentive to infiltrating a fine plutonium powder through a $\mathrm{UO}_{2}$ packed-particle element during the last stages of fabrication in order to reduce the amount of plutonium handling required. This process is being investigated within Euratom and has been worked on under the Plutonium Utilization Program. It is therefore desirable that it be permissible to use mixed oxide fuel in as 


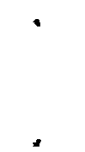


heterogeneous a state as is safe from physics and heat transfer considerations. The fuel elements now in the PRTR, the EBWR, and part of the Saxton Reactor are composed of mixed oxide in which the $\mathrm{PuO}_{2}$ is present as small particles, about $40 \mu$ diameter, dispersed in $\mathrm{UO}_{2}$. Although for these particular applications conservative calculations indicate the fuel is safe, it is not known how much more heterogeneous it would be permissible to make the fuel. If the effect of heterogeneity on reactivity is appreciable, an accurate determination of the reactivity effects would be important in the nuclear design of a power reactor employing this type of fuel. Possible diffusion of the $\mathrm{PuO}_{2}$ particles into the $\mathrm{UO}_{2}$ could produce reactivity transient effects during power operation. Calculations of particle separation effects on reactivity are difficult and necessarily involve assumptions which need to be checked by comparing the calculationsal results with experimental results. A series of experiments are being initiated that will provide experimental data for evaluating the effects (See Task P-5).

Reactivity effects of particles in the size range of 0 to $700 \mathrm{microns}$ will be measured. Fuel elements containing 2 wt $\mathrm{PuO}_{2}-\mathrm{UO}_{2}$ with plutonium having a $\mathrm{Pu}^{240}$ concentration of $\sim 8 \%$ and $\sim 20 \%$ will be used in the experiments. Another experiment to determine the reactivity effects of fuel diffusion properties and particle size changes with irradiation is being considered.

Fuel Fabrication Studies

Incremental Cost Evaluation

One of the first goals of the Plutonium Recycle Program was to determine the incremental cost of fabricating plutonium bearing fuel elements. A recently completed study which considers both pellet and packed particle fuel element fabrication with high and low exposure plutonium* in an approximately one ton per day plant has been completed The incremental cost for plutonium bearing fuel elements has been computed to be in the $20-25 \%$ range for large scale operation. Further work to define the effects of throughput on cost is now in progress (See Task FD-5).

Radiation Problems with High Exposure Plutonium

Although considerable experience has been gained in handling plutonium containing high $\mathrm{Pu}^{240}$, the problems associated with the handling of actual high burnup plutonium (containing significant amounts of $\mathrm{Pu}^{238}$ and other isotopes) are not completely resolved. In order to answer the remaining questions, a program is planned with the following objectives: (1) to recover and analyze the minimum necessary quantities of plutonium from available irradiated power reactor fuels to obtain material of known history, composition, and neutron exposure; (2) to determine the neutron and ionizing dose rates from specimens of the recovered plutonium in the forms of metal and compounds conventionally used in fuel element fabrication and to use these data to develop accurate mathematical models for predicting the radiation levels associated with plutonium compounds of any isotopic condition; (3) to determine the shielding effectiveness of various materials used in the manipulation of plutonium

* For definition of high and low exposure plutonium see Task FD-4 


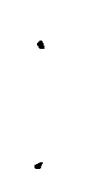


enriched fuels; (4) to measure neutron multiplication in nonmoderated assemblies of existing fuel rods and plates; and (5) to provide isotopic composition data to test computer programs devised for calculating isotopic ratios in plutonium produced in power reactor fuels arter extended exposure and recycling (See Task FD-4).

Advanced Plutonium Fuel Development

Cortain novel fuel element concepts scom to offer economic advantages for plutonium utilization (See Task FD-10). Iho inverted cluster design offers the advantages of a relatively low cost jacketing system and low cost fabrication when used in combination with librational compaction. This latter point can be important if problems are cncountered with high radiation dose mass from nigh exposurc plutonium. The wirc curichment or "pencil" enrichment concept offers a major advantage for prolonging the $1 \mathrm{ife}$ of a fuel charge and reducing fuel fabrication costs. It provides the potential for deferring plutoniun handling to the last steps of fuel rod fabrication. This system lurther provides for very close matiching of the burnup rates of plutonium and $u^{235}$. This reduces reactivity and heat generation mismatches that are currently reflected in the published plutonium values of $\$ 8$ to $\$ 1$ ] per gram.

liconomic analyses, from an overall fuel cycle standpoint, are first steps in evaluating these fuel element concepts. Fuel element design studies, fabrication of experimental fuel elements, and limited irradiation testing wi 11 fo11ow.

\section{Particle Agglomeration Process}

The present fuel preparation process used at Battelle-Northwest involves pneumatic impaction to obtain high density particles. Although this process appears to be the cheapest process now available for producing mixed oxides for the vibrational compaction fabrication process, a cheaper process might resuit from the development of a continuous particle agglomeration technique coupled with a continuous sintering process (See Task FD-11). In particle agglomeration a mixture of fine $\mathrm{UO}_{2}$ and $\mathrm{PuO}_{2}$ powder is tumbled until it "snowballs" into the desired size particles. The agglomerated particles can then be sintered to give them mechanical strength and used as feed material for vibrationa 1 compaction. A program has been started to develop agglomerates of $\mathrm{UO}_{2}$, and the technique is now being extended to $\mathrm{UO}_{2}-\mathrm{PuO}_{2}$. Successful development of this process could result in a major breakthrough in reducing cost of plutonium-bearing elements.

Demonstration of Fuel Performance PRTR Batch Core Experiment

Irradiation induced phenomena, such as fuel relocation and plutonium or fission product migration, could result in a troublesome operational problem in a full-core loading whereas their effects on a sirgle fucl element basis may be insignificant. The Batch Core Experiment will provide statistically significant irradiation behavior data on plutonium-bearing fuels operating at rod powers as high as $20 \mathrm{~kW} / \mathrm{ft}(54$ $\mathrm{kW} / \mathrm{kg}$ of fuel) to exposures up to approximate1y 13,000 MWd/MT (See Task FD-1). Maximum fuel temperatures ( 2600 to $2800{ }^{\circ} \mathrm{C}$ ) will be near melting. This experiment should provide sufficient data to resolve the more important questions concerning the basic 

feasibility of operating ful1-core loadings of plutonium-bearing fuels at specific powers and to exposures of interest to commercial power reactors.

An important aspect of the Batch Core Experiment in the PRTR will be comparative data on performance of powder and pellet fuels. Although the great majority of the fuel elements in the core will be of the packed-powder variety, rods of pelleted fuel will be included in various powder-fue 1 19-rod clusters and complete pellet fuel 19rod clusters (See Task IA-1). The single rods interspersed among the powderfuel elements in the PRTR core will be used as "source" irradiated rods for special tests such as defect testing and high specific power tests in the FERTF. The fue 1 elements containing all pellet fuel will be operated at as high specific power as permissible within the core of the PRTR and to as high a burnup as possible. Performance of these elements can them be compared to that of similarly operated powder fuel elements.

There are several important questions, particularly of a safety nature, that surround the use of plutonium enrichment. Fuel relocation, slumping, and plutonium migration or segregation may result in reactivity changes leading to operating problems. Plutonium additions may affect fuel plasticity and long-term creep and, and consequently, fuel relocation and swelling. Fue 1 thermal conductivity and hence fission gas release and internal pressure within the fuel rods during operation may also be affected by plutonium additions. Two of the elements in the Batch Core will be equipped with pressure sensing devices to measure inter- nal gas pressure during irradiation (See Task FD-7). Corrosion, dimensional stability, fission product migration and fuel structures will also be studied.

In addition to the irradiation of the 66 element Batch Core, special irradiation tests will be performed in the peripheral positions. These tests include continued irradiation of $\mathrm{UO}_{2}{ }^{-}$ $\mathrm{PuO}_{2}$ elements containing $0.48,1.0$, and 2.0 wt: $\mathrm{PuO}_{2}$ of a $\mathrm{ThO}_{2}-5$ wt: $\mathrm{PuO}_{2}$, element instrumented with internal gas pressure sensing devices, and of other advanced fuel element concepts (See Task FD-12). Related tests will be conducted in the MTR and ETR to provide substantiating high burnup and high power data on plutonium fuel element designs under investigation in the PUP (See Task FD-8).

FERTF Irradiations

Special $\mathrm{UO}_{2}-\mathrm{PuO}_{2}$ test elements will be irradiated in the centrally located Fue1 Element Rupture Test Facility (FERTF) at maximum specific powers to $30 \mathrm{~kW} / \mathrm{ft}(80 \mathrm{~kW} / \mathrm{kg}$, significant fue 1 melting) (See Task FD-2). One of the primary objectives of these experiments is to determine whether plutonium-bearing oxide fuels are limited to powers and exposures less than those attainable with enriched-uranium oxide fue1s. FERTF experiments will also provide a source of fuel rods to study possible reactivity effects of molten fuel operation.

Some of the effects to be investigated for molten fuel operation are: possibility of plutonium migration or segregation from the liquid phase; fuel volatility (possibility of selective vaporization and vapor phase partial 


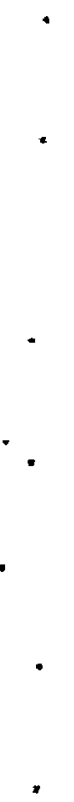


fractionation of plutonium); fission product migration; fission gas release; fuel plasticity and its consequent effect on fuel rod swelling and fuel relocation or slumping; and molten fuel viscosity and its effect on mobility and ability to flow into cracks in fuel in close proximity to the cladding.

Transient jehavior of irradiated pellet and powder fuels previously opcrated in the molten and nonmolten conditions to about $15,000 \mathrm{MWd} / \mathrm{MT}$ will be studied in TREAT experiments (See Task FD-9). The phenomena of fue 1 slumping and/or relocation in rods tested short of destruction as well as the dispersal and chemical reactivity properties of fuel released from rapidly ruptured rods will be investigated. Fuel Rupture Consequences

Since a commercial power reactor cannot be operated economically without allowing the presence of in-core "leaker" fuel elements, it is imperative that the operating characteristics of defected fuel elements be investigated in sufficient depth to enable definition of their operating $1 \mathrm{imits}$.

Packed particle $\mathrm{UO}_{2}$ and $\mathrm{UO}_{2}-\mathrm{PuO}_{2}$ fuel olements have been operated with defects ranging from $1 / 16$ in. holes up to 3-1/2 in. 1ong slits at rod powers to $27 \mathrm{~kW} / \mathrm{ft}$. The most notable observation is the lack of washout or water logging of these fuels. However, information obtained from the recent failure of an intentionally-defected fuel rod operating at high specific power $(27 \mathrm{~kW} / \mathrm{ft})$ indicates the need for more studies on the behavior of defected fuel rods. The fuel apparently was oxidized under conditions that were not previously assumed conducive to oxidation. The oxidation of the fuel caused higher fuel temperatures and fuel expansion in excess of that for which the rod was designed. More information is needed concerning the effect of the size and shape of the defect, fuel surface temperature and power generation, bulk fuel density, burnup, fuel form (powder, pellet), and fuel type $\left(\mathrm{UO}_{2}, \mathrm{UO}_{2}-\mathrm{PuO}_{2}\right)$.

A significant set of FERTF experiments will yield a direct comparison of the defert operating characteristics at various power generations of $\mathrm{UO}_{2}$ and $\mathrm{UO}_{2}-\mathrm{PuO}_{2}$ in packed-powder and pellet form (See Task FD-2). Fue1 rods wil1 be operated with intentional defects at power generations from about 20 to $30 \mathrm{~kW} / \mathrm{ft}$, the latter resulting in a significant degree of fuel melting. Performance data on fuel washout, waterlogging, and fuel rod swelling of experimental rods incorporating the variables 1 isted above will be of great value to power reactor operators.

Another variable to be tested in the FERTF irradiations is fuel stoichiometry. As pointed out above, effects of stoichiometry on thermal conductivity may relate directly to the defect behavior of the oxide fuel. It is also possible that hypostoichiometric fuel wil1 allow higher power generations than stoichiometric fuel for the same maximum fuel temperature.

\section{EBWR Demonstration and Associated}

Studies

The fuels development portion of the EBWR program is being piloted by capsule and fuel element irradiations in other reactors tc $\therefore$ goal exposure as high as $27,500 \mathrm{MWd} / \mathrm{t}$ on of fuel and up 


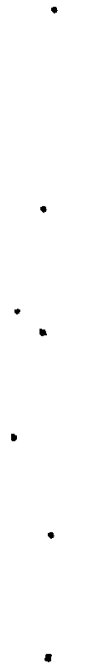


to specific powers well beyond those anticipated for EBWR (yielding central melting). These irradiations will be completed within 18 months and subsequent examinations will provide the first systematic study of the fission gas release, swelling, and releated behavior of plutonium fuels at high burnups and under a variety of powers (See Task PRD-1). Capsule irradiations to date have attained a maximum exposure of $24,500 \mathrm{MWd} / \mathrm{ton}$ and the fuel rod irradiations have reached $2500 \mathrm{MWd} / \mathrm{ton}$.

The irradiation program in the EBWR will be carried to about $12,000 \mathrm{MWd} / \mathrm{ton}$. An important aspect will be intermittent examination of the irradiated fuel rods. Comparison with capsule irradiation data, especially fission gas release characteristics, will be of great interest.

\section{Reactor Decontamination}

Significant progress has been made in developing procedures for the noncorrosive decontamination of reactor coolant systems containing particulate plutonium ceramics, but more work is needed (See Task MD-1). The recent decontamination of the PRTR primary coolant system to remove adhered corrosion product films (deposited during routine reactor operation and not associated with FFRTF testing or the abovementioned fuel rod rupture) demonstrated high decontamination factors ranging from 5 to 200 with an average throughout the system of approximately 25. The overall decontamination achieved exceeds any results reported in other reactor coolant system decontaminations.
Optimization of Reactor and Core

Designs for Plutonium

Battelle-Northwest cycle analysis studies have provided effective models for studying utilization of plutonium as a fuel over a wide range of design and operating parameters. It is desirable that this work be continued (See Task CA-1). As the Plutonium Utilization Program approaches termination, physics-type models should be evaluated in the environment of engineered systems and accompanying economics.

In BWR's and PWR's a change in the moderator-to- $U^{238}$ ratio is indicated for plutonium fueling. Accordingly, possible core design changes to optimize for plutonium include use of larger cores, lower density fuel, smaller fuel pins, or a combination of these. Plutonium fueling will tend to increase control span required for burnup compensation in BWR's and PWR's. The effect of plutonium fueling on control needs for typical fuel management schemes has not been assessed in terms of number of rods, the use of soluble poisons, and effects on power distribution, all of which tend to diminish the savings predicted from general surveys.

The planned analysis will include studies of the reactivity worth of plutonium in various fue 1 configurations, possible power flattening through preferential placement of plutonium, lattice spacing, effects of reduced fuel density, shielding effects, and constant reactivity fuels. The most promising schemes will be examined in specific detail, and core and reaccor design recommendations for optimizing 

plutonium recycle will be made (See Task RED-1). These studies will be based, to the extent possible, on the range of parameters representative of the plants expected to be in operation in the 1970's to $1980^{\prime} \mathrm{s}$.

\section{Industrial Assistance}

Additional work is being planned over the next few years to assure timely transfer of detailed knowledge from the Plutonium Utilization Program to industry. This will be accomplished by maintaining a continuous close communjcations with industry to assure that the Plutonium Utilization Program will answer the most crucial questions about plutonium recycle.

Based on recent contacts with industrial representatives, we plan to conduct critical experiments on $\mathrm{UO}_{2}-4 \%$ $\mathrm{PuO}_{2}$ fuel rods, a concentration of specific interest to the nuclear industry (See Task 1A-5). Reactivity, power peaking, power sharing, control rod worth, and other engineering parameters important to reactor designers will be determined (See Tasks IA-2 and IA-3).

Single region experiments with boron in the $\mathrm{H}_{2} \mathrm{O}$ moderator will be conducted with selected 2 wt $\mathrm{PuO}_{2}$ and 5 wt: and 2 wt: Pu-Al fuel elements to reduce the neutron leakage effect of small cores (See Task IA-4). Industria11y designed and fabricated pellet fuel rods will be included in the Batch Core (See Task (IA-1). Additional pellet rods will be tested in the FERTF.

Other work will be considered under the Plutonium Utilization Program for which Battelle-Northwest has special facilities or capabilities. Examples are monitoring of commercial fuel element designs and checking of physics calculations. Other work may consist of analysis of fuel conversion steps, fuel fabrication, and separations processes associated with industrial plutonium recycle problems.

Consideration will also be given to having industry perform Plutonium Utilization Program tasks for which industry has special competence. 

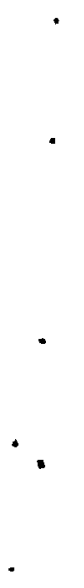


\section{PROGRAM R\&D SCHEDULE}

(Items in direct support of Test Reactor Operation are not included)

Task

Number

Number

FD - 1

$-2$

$-4$

$-5$

$-7$

$-8$

$-9$

$-10$

$-11$

$-12$

MD- 1

RED - 1

PRD - 1

$-2$

I A - 1

$-2$

$-3$

$-4$

$-5$

P - 1

$-2$

$-3$

$-4$

$-5$

$-6$

CA - 1
Reference $189 \mathrm{a}$ and Task Title

TEST REACTOR OPERATION (PRTR)

CRITICAL FACILITY OPERATION

FUELS DEVELOPMENT

$$
\text { Batch Core Testing }
$$

FERTF Testing

High Exposure Plutonium Studies

Fuel Element Fabrication Cost Studies

Special Batch Core Testing

MTR/ETR Testing

Transient Tests (TREAT)

Advanced Fuel Development

Advanced Fabrication Studies

PRTR Fringe Positions

MATERIALS DEVELOPMENT

Plutonium Decontamination Studies

REACTOR ENGINEERING DEVELOPMENT

Design Analys is

PLUTONIUM RECYCLE DEMONSTRATION (EBWR)

Fue1 Irradiations

EBWR Experiment

INDUSTRIAL ASSISTANCE

Commercial Fuels Study

Water Gap and Control Rod Measurements

Power Sharing Experiments

Measurements with Boronated Moderator

Measurements with $4 \% \mathrm{PuO}_{2}-\mathrm{UO}_{2}$ Fuel

(Additional tasks are expected to develop)

REACTOR PHYSICS

Subcritica 1 and Critical Experiments

Irradiation Experiments

Methods Development

Methods Evaluation

Particle Size Effects

PRTR Batch Core Experiment

CYCLE ANALYSIS

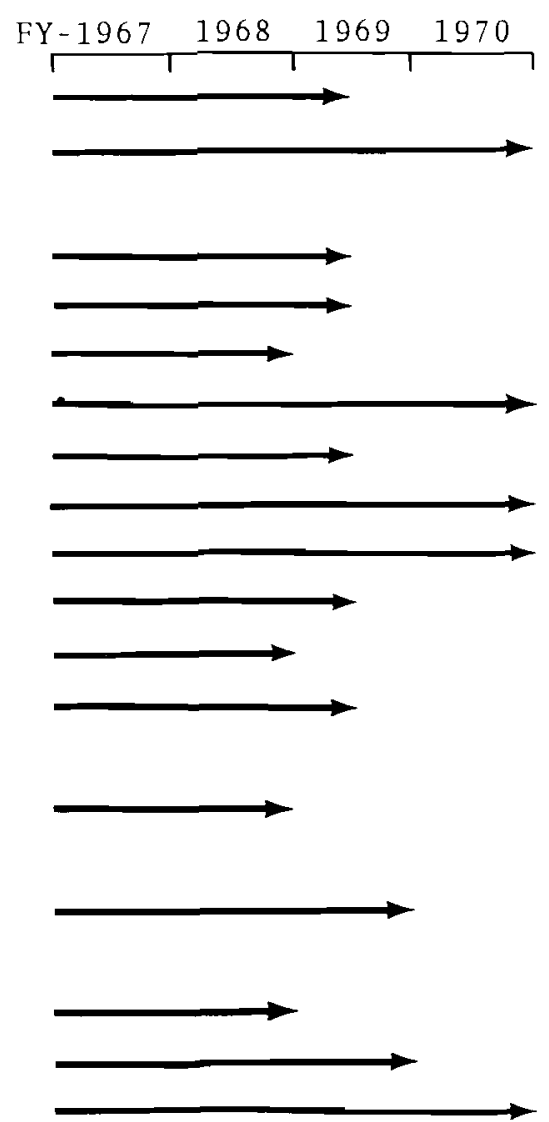



REFERENCE 189: Plutonium Utilization Program

Fue 1s Development

SCOPE: Irradiate $\mathrm{UO}_{2}-\mathrm{PuO}_{2}$ fuel elements at maximum 1 inear power generations of approximately $20 \mathrm{~kW} / \mathrm{ft}$ to exposures of approximately $13,000 \mathrm{MWd} / \mathrm{MT}$. Maintain surveillance of Batch Core fuel elements by underwater visual examination and destructive postirradiation examination. Provide irradiated test rods for use in FERTF, TREAT, and PRCF experiments.

OBJECTIVE AND JUSTIFICATION: The major objective is to obtain statistically significant irradiation behavior data on $\mathrm{UO}_{2}-\mathrm{PuO}_{2}$ fue 1 rods operated at power generations greater than those employed in present commercial power reactors.

The Batch Core Experiment will provide statistically significant performance data on $\mathrm{UO}_{2}-\mathrm{PuO}_{2}$ fuel elements operated at 1 inear rod powers to approximately $20 \mathrm{~kW} / \mathrm{ft}$ to maximum burnups of approximately 13,000 MWd/MT. Maximum fue 1 temperatures $\left(2600\right.$ to $\left.280{ }^{\circ} \mathrm{C}\right)$ will be near melting. Operation under these conditions will provide needed information concerning the basic feasibility of operating full core loadings of plutonium-bearing fuels at specific powers and to exposures of interest to commercial power reactors.

There are several important areas related to fuel behavior that surround the use of a plutonium-enrichment that will be investigated during the Batch Core Experiment. These include fuel relocation, slumping, and plutonium migration or segregation, which may lead to operating problems when manifested in a significant number of elements. Plutonium additions may affect fuel plasticity and long-term creep and consequently fuel relocation and rod swelling. Plutonium additions may also affect the thermal conductivity of the fuel and hence, the operating temperatures and fission gas release characteristics. Long-term corrosion behavior, dimensional stability, and fission product migration and fuel structures will also be studied during the Batch Core Experiment.

An important aspect of these Batch Core Experiment in PRTR will be an evaluation of the comparative performance of vibrationally-compacted and pellet fuels. Although the great majority of the 66 fuel elements in the core will be of the packed-powder variety, two commercially procured pellet fuel elements, as well as several single-rods interspersed among the powder fuel elements, will be irradiated in the PRTR core. Some of these irradiated rods will be used later for special tests such as subsequent irradiation in the FERTF, defect testing in the FERTF, PRCF experiments, and transient testing in TREAT. 


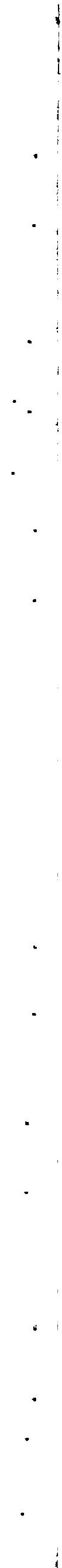


REFERENCE 189: Plutonium Utilization Program

Fue1s Development

SCOPE: Peform irradiation tests of $\mathrm{UO}_{2}-\mathrm{PuO}_{2}$ fuel rods in the Fuel Element Rupture Test Facility (FERTF). The test program includes variations of three important parameters: (1) fuel form (powder, pel1et); (2) power generation (20 to $30 \mathrm{~kW} / \mathrm{ft}$ ); and (3) defect behavior. The FERTF tests will also serve as a source of irradiated rods for use in PRCF and TREAT experiments. Rods previously irradiated in the PRTR core, as well as unirradiated rods, will be tested in the FERTF.

OBJECTIVE AND JUSTIFICATION: One of the primary objectives of these experiments is to determine whether plutonium-enriched oxide fuels are limited to powers and/or exposures less than those attainable with uranium-enriched oxide fuels. Another important objective is the direct comparison of the irradiation behavior of pelleted and packed-powder fuel rods. An intense effort will be put forth to define the operating limits of defected oxide fuel rods.

High power generation experiments performed by GE-APED on nondefected $\mathrm{UO}_{2}$ fuel rods showed that proper design would allow steady-state operation at linear rod powers on the order of $40 \mathrm{~kW} / \mathrm{ft}$ to burnups greater than $20,000 \mathrm{MWd} / \mathrm{MT}$. If thermal recycle of plutonium is to take place, the performance of the plutoniumbearing fuel elements must be competitive with that of fuel elements enriched with uranium. In response to a request that they comment on the BNW plans for the Plutonium Utilization Program, one industrial fuel manufacturer stated: "To be of value to water-cooled thermal reactors and to demonstrate competitiveness with $\mathrm{UO}_{2}$ fuels, the irradiations of industrially supplied fuel should attain a minimum exposure of $15,000 \mathrm{MWd} / \mathrm{ton}$ (average) and should demonstrate ability to operate with sustained fuel central melting."

To be of importance to industry, a determination must be made of the relative performance of the commonly used pellet form of oxide fuel and the vibrationallycompacted form which has thus far been employed in the Plutonium Utilization Program. The general technical and economic feasibility of the latter fuel has been demonstrated, it now remains to make a side-by-side comparison with the industrially-used pellet fuel.

Since no commercial reactor can be operated economically without accommodating defective fuel rods, the study of fuel rod defect behavior is an important part of the Fuels Development Program. It is vitally important to determine limits of operability with defects, so that commercial reactor operators are able to maintain optimum operating efficiency and power density. The effects, in particular, of specific power, burnup, and fuel form will be investigated. The defect behavior is an important consideration in the comparative performance evaluation of pellet and packed-powder fuel.

The performance data to be derived include fuel washout characteristics, waterlogging, fuel rod swelling, radial and axial fuel relocation, fission product and/or plutonium migration, plutonium segregation from the 1iquid, fuel volatility, fission gas release, fuel plasticity and its consequent effect on fuel rod swelling, fuel viscosity as it affects mobility and ability to flow into cracks, and convection mixing in the molten fuel region. Another important variable to be investigated is fuel stoichiometry and its effect on thermal conductivity and fuel temperature distribution. 


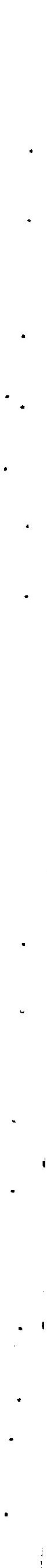


REFERENCE 189: Plutonium Utilization Program

Fuels Development

SCOPE: This task consists of characterizing high exposure plutonium* and then fabricating fuel elements enriched by this material. Characterization will include establishing radiation levels, dose rates, and shielding requirements on representative samples of available material. Based on these results, the characteristics of fuel material of known exposure history will be calculated using computer techniques.

Shippingport, Yankee, and Dresden irradiated fuel, representative of boiling water and pressurized water reactors, and other fuels of specific interest to the study will be sampled.

OBJECTIVE AND JUSTIFICATION: A major area of interest in the nuclear fuel fabrication field involves the use of high exposure plutonium in the production of fuel elements for thermal and fast reactors.

Due to the increasing quantities of high exposure plutonium forecast in the United States within the next decade or two, experience. in handiing and refabricating this type material is vital. Experience has been obtained in the handling and refabricating of plutonium containing high Pu240, recovered from $\mathrm{Pu}$ alloy fuel. However, the extent of the handling problems associated with plutgnium produced during long-term irradiation of ceramic fuel (high Pu238; Pu236) containing $\mathrm{U}^{235}$ and $\mathrm{U}^{2} 38$ is undetermined.

The basic objective is to obtain experimental data for evaluating the radiation levels associated with plutonium that is produced during extended exposures in power reactors.

Secondary objectives to be achieved under the scope of the study include:

- Determination of shielding requirements for fuel element fabrication operations.

- Determination of isotopic composition by sampling and analysis.

- Improvement of plutonium handling and fabrication technology.

- Test of computer programs to predict radiation levels, shielding requirements, and isotopic compositions for various exposure histories.

High and Low Exposure Plutonium

For the purpose of this study high and low exposure plutonium are defined below:

Material with over $80 \% \mathrm{Pu}^{239}$ is considered as 10 w exposure Pu. Low exposure plutonium is that which may typically result from special runs in production reactors or from exposure of slightly enriched uranium fuel in $\frac{1}{2}$ ght water moderated power reactors to less than about $10,000 \mathrm{MWd} / \mathrm{ton}$. Pu 24 content will generally be less than $12 \%$ and $\mathrm{Pu} 238$ content will typically be less than $1 / 2 \%$.

Material with less than $80 \% \mathrm{Pu}^{239}$ is considered as high exposure Pu. High exposure plutonium is that which may typically result from discharge of slightly enriched fuel from light water moderated power reactors at exposures beyond $20,000 \mathrm{MWd} / \mathrm{ton}$. Pu240 content wi11 genera11y run $15-25 \%$ and Pu 238 content may be greater than $1 / 2 \%$ and perhaps as high as $5 \%$.

\footnotetext{
* See definition of high and low exposure Pu given below.
} 

Other isotopes such as $\mathrm{Pu} 236, \mathrm{Pu}^{241}$, and $\mathrm{Pu}^{242}$ also contribute to the radiation dose and handing problems to some degree but they are not now considered in the definition of high and low exposure plutonium due to lack of information. The effect of $\mathrm{Pu}_{241}$ increases with time after separation due to build-in of daughter products. The Pu236 and Pu242 likely contribute less to the irradiation dose than do the $\mathrm{Pu} 238$ and $\mathrm{Pu}^{240}$. 
.

. 
REFERENCE 189: Plutonium Utilization Program

Fuels Development

SCOPE: The scope of this work includes compilation and dissemination of actual costs on pilot-scale fuel element fabrication jobs, estimation of costs on the basis of production-scale fabrication; e.g., l Ton/Day plant, and estimation of incremental costs on the basis of new fuel element designs and processes.

OBJECTIVE AND JUSTIFICATION: The objective is to provide fuel element fabrication cost information on the basis of fabrication experience and other data.

One of the first goals of the Plutonium Utilization Program was to determine the incremental cost of fabricating plutonium fuel elements. For low exposure plutonium this has been established to be in the $20-25 \%$ range for pilot-scale operation. Further studies will be required to determine costs associated with fabricating the more radioactive high exposure plutonium, which results from irradiation of plutonium-bearing ceramic fuels in commercial power reactors and to examine the effects of throughput on fabrication costs. Enough experience is available with fuels of high Pu240 content to indicate that the total incremental fabrication costs will not be a deterrent to the utilization of plutonium fuels. 


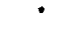


REFERENCE 189: Plutonium Utilization Program

Fuels Development

SCOPE: Perform special irradiation tests within the Batch Core in addition to those tests required for successful completion of the Batch Core Testing Task. At present, two rods each in two fuel elements are equipped with instrumentation to continually measure the gas pressure and temperature within the plenums of the rods. Irradiation of these two fuel elements currently constitutes the Special Batch Core Testing Tas.k.

OBJECTIVE AND JUSTIFICATION: The major objective is to obtain data on the plenum gas temperature and pressure existing in fuel rods during irradiation at various power generations to various exposures. Such information will aid greatly in future fuel rod design efforts, particularly in relation to fission gas plenum design and cladding strength criteria.

Two rods, included in each of two vibrationally-compacted $\mathrm{UO}_{2}-2 \% \mathrm{PuO}_{2}$ Batch Core fuel elements, are equipped with thermocouples and pressure indicating devices to measure and record plenum gas temperature and pressure within the rods during irradiation in PRTR. The elements will be positioned in the PRTR core to operate at different power generations in an effort to determine the effect of fuel temperatures on fission gas release. Maximum fuel temperatures in one of the elements will be near melting. It is planned to continue the tests throughout the duration of the Batch Core Experiment to investigate long-term effects. At the completion of the test, the instrumented rods and some of the noninstrumented rods will be destructively examined to attempt to correlate fission gas release characteristics with fuel structures formed during irradiation. 


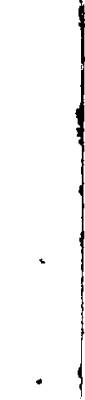


BNWL - 298

TASK: MTR/ETR TESTING

TASK NUMBER: FD-8

REFERENCE 189: Plutonium Utilization Program

Fuels Development

SCOPE: Perform capsule and loop irradiations in MTR/ETR to provide additional information in support of the Plutonium Utilization Program. Experiments incorporating several variables, new concepts, and/or unusual operating conditions are particularly suited to testing in MTR/ETR. "Screening" tests are best performed in these reactors.

OBJECTIVE AND JUSTIFICATION: The major objective of this is to supplement irradiations in PRTR and to obtain data which are difficult or impractical to derive from PRTR irradiations. Short-term investigations of specific items, under adjustable operating conditions, form a large part of this task.

The MTR/ETR affords multiple test irradiation on an adjustable time basis and is especially well suited to "screening" tests in advance of intended irradiation in PRTR. The screening tests are also very useful when considering new fuel element concepts or high-risk experiments.

Examples of tests which have been performed at MTR/ETR which fall into several of the categories listed above are: molten fuel impingement "rabbit" irradiations, tests of the wire-enriched fuel rod concept, chloride impurity test capsules, molten fuel defect tests, and the plutonium diffusion tests. 
· 
REFERENCE 189: p1utonium Utilization Program

Fuels Development

SCOPE: Perform transient experiments of irradiated and nonirradiated fuel rods containing pelleted as well as vibrationally-compacted fuel. The transient test rods will include variations of three important parameters: (1) fuel form (pellet, powder); (2) burnup (nominally 0,3000, and 10,000 MWd/MT); and (3) power generation during pre-TREAT irradiation (molten and nonmolten fuel).

OBJECTIVE AND JUSTIFICATION: The major objective is to investigate fuel relocation in rods tested short of rupture. The dispersal and chemical reactivity properties of fuel relased from rapidly ruptured rods will also be investigated.

The phenomenon of fuel relocation has bearing on both the nuclear safety and mechanical integrity of fuel rods. In the former case, "slumping" during a transient could aggravate the transient and result in an uncontrollable condition. In the latter case, "slumped" fuel could cause catastrophic swelling in rods during startup or sustained operation following the slump-inducing transient.

The dispersal and chemical reactivity properties of fuel released from ruptured rods influence the rate and amount of steam and/or reaction-product-gas formation and hence the magnitude and duration of a resultant pressure pulse. These properties may also affect rupture propagation. 


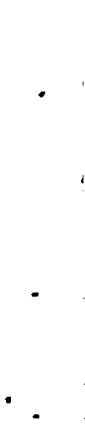

. 
SCOPE: This task consists of advanced fuel element design studies, laboratory process development, fabrication of experimental fuel elements, and irradiation testing of novel fuel element concepts such as the inverted cluster and the self-shielded or plutonium "pencil" concept. Economic analyses, from an overall plutonium utilization standpoint, will be used to focus development work on the most promising concept.

OBJECTIVE AND JUSTIFICATION: The objective of this task is to provide engineering and economic evaluations for only the most promising advanced fuel element concepts. BNW analysis studies have provided models for optimum utilization of plutonium as a fuel over a wide range of design and operating parameters. As the PUP approaches termination, these models, representing fuel element design concepts with high potential, must be evaluated in the environment of engineered systems and accompanying economics. The inverted cluster and wire or "pencil" enrichment concepts are two specific advanced fuel element designs which warrant demonstration.

The inverted cluster design offers the advantages of: 1) low cost jacketing system with high heat transfer area; 2) allowing high pressure coolants without requiring heavy wall process tubes; 3) minimizing absorption in jacketing materials to improve uranium conservation; 4) utilizing existing fabrication technology and facilities; and, 5) yielding low fabrication costs with vibratory compaction of ceramic fuels. Applications include large PWRs such as those currently envisioned for desalination, HWOCRs, sodium cooled graphite systems and superheated steam graphite systems.

The wire enrichment concept offers the major advantages of prolonging the life of a fuel charge and reducing fuel fabrication costs. From the physics point of view, any situation using plutonium fuel looks more attractive with the pencil copfiguration. Applications include PWR, BWR, HWOCR, HTGR, and startup of $\mathrm{U}^{233}$ - thorium cycles. 


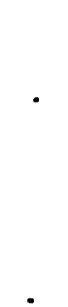

. 
TASK: ADVANCED FABRICATION STUDIES

TASK NUMBER: FD-11

\author{
REFERENCE 189: Plutonium Utilization Program \\ Fuels Development
}

SCOPE: This task consists of developing an agglomeration-sintering process for preparing high density fuel particles.

OBJECTIVE AND JUSTIFICATION: The objective of this subprogram is to develop an improved plutonium fuel element fabrication process which will result in less cost.

The present fuel process used at Battelle-Northwest involves pneumatic impaction to obtain high density particles. Although this process appears to be the cheapest process now available for producing mixed oxides, if used in conjunction with a vibrational compaction fabrication process, a cheaper process might result from the development of a continuous particle agglomeration technique coupled with a continuous sintering process. The process is particularly adaptable to automated semiremote operation and yields spherical particles of controllable size which should be particularly suitable for vibrational compaction. 


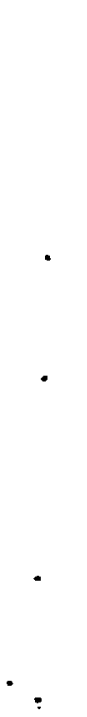


REFERENCE 189: Plutonium Utilization Program

Fuels Development

SCOPE: Perform high burnup evaluation of fuel elements of various designs and types by continued irradiation of selected fuel elements which were in PRTR at time of shutdown and change to the Batch Core. Utilize fringe positions to irradiate fuel elements and rods intended as replacements for Batch Core Experiment fuel elements and rods that are discharged from the Batch Core Experiment. Tests of FERTF, special, and advanced fuel element designs will a1so be accommodated.

OBJECTIVE AND JUSTIFICATION: Irradiation of a few selected first generation PRTR fuel elements was continued during operation of PRTR to obtain high burnup data on plutonium-containing fuels of interest to the commercial utilization of plutonium recycle in thermal reactors. Continued irradiation of these elements to the highest attainable burnup is an important goal of the plutonium fuels program since burnups in the range of 20,000 MWd/MT are of interest to commercial power reactors. The irradiation behavior of an instrumented $\mathrm{ThO}_{2}-\mathrm{PuO}_{2}$ fuel element is also being investigated since this fuel material is of interest in crossed progeny fuel cycles.

A special test element containing 21 full-size EBWR fuel rods has been irradiated in the PRTR to a burnup of $2690 \mathrm{MWd} / \mathrm{MT}$ in support of the cooperative ANL-BNW Plutonium Utilization Demonstration Experiment in the Experimental Boiling Water Reactor. Irradiation of this element will be continued in a fringe position of the PRTR. The purpose of the experiment is to obtain information useful for the utilization of plutonium as a fuel in Iight water thermal reactor systems. The goal burnup for this element is $\geq 11,000 \mathrm{MWd} / \mathrm{MT}$. It is planned to remove rods at burnups of $5500 \mathrm{MWd} / \mathrm{MT}, 11, \overline{0} 00 \mathrm{MWd} / \mathrm{MT}$, and possibly $16,500 \mathrm{MWd} / \mathrm{MT}$ for destructive examination. Removed rods will be replaced by fresh rods.

Special assemblies will be irradiated in PRTR fringe positions to supply test fuel rods for experiments in the FERTF. 


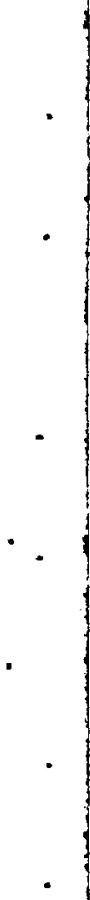




\section{REFERENCE 189: Plutonium Utilization Program Materia1s Development}

SCOPE: Procedures have been developed for decontaminating many reactors, but the procedures are inadequate for plutonium-fueled reactors because common decontaminating reagents are ineffective in dissolving plutonium refactory ceramics such as $\mathrm{PuO}_{2}$. Conventional fuel reprocessing solutions are excessively corrosive to many cominonly used reactor components. The kinetics and mechanisms of ceramic fuel dissolution must be studied to develop efficient and safe procedures for dissolving and removing rupture debris without damaging reactor components.

OBJECTIVE AND JUSTIFICATION: Determine the kinetics of ceramic fuel dissolution such as might be required for removal of fuel rupture debris. Improved procedures will be developed to dissolve ceramic oxides containing Pu, and procedures optimized for decontamination and removal of rupture debris. The effects of the physical properties of mixed oxides, including particle size, on dissolution will be explored. The corrosion of reactor structural materials in candidate procedures will be determined and procedures will be adapted for use in reactor systems with emphasis on those composed of stainless steel and zircaloy-2. 


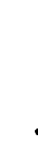

•

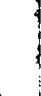

.

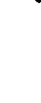


TASK: DESIGN ANALYSIS

TASK NUMBER: RED-1

REFERENCE 189: Plutonium Utilization Program

Reactor Engineering Development

SCOPE: Analysis effort under the Plutonium Utilization Program is intended to provide input to the general problem of optimum utilization of plutonium in Boiling Water Reactors (BWR's) and Pressurized Water Reactors (PWR's) typical of those that will be operating during the decade, 1970-1980.

Preliminary optimization will include studies of reactivity, power distribution, and core $1 \mathrm{ife}$ of each reactor for various fuel enrichments and configurations that fall within limits imposed by the range of design parameters specified from fuel cycle studies and operating experience with pu fuels in the PRTR. The most promising fueling schemes will be examined in specific detail to ascertain control and safety requirements, kinetic behavior, and heat transfer and coolant requirements. Finally, specific recommendations for optimizing plutonium recycle will be made and comparisons will be made between the most favorable fueling scheme devised within the design constraints of a specific reactor and the optimum schemes predicted in previous survey calculations.

OBJECTIVES AND JUSTIFICATION: A major objective is to further the development of plutonium as a commercial power reactor fuel. From fuel cycle studies over a wide range of design and operating parameters and from previous PRTR operating experience, general conclusions have been reached about optimum utilization of plutonium in thermal, water-moderated, power reactors. These general conclusions must be translated into specific core designs if thermal plutonium recycle is to begin in the 1970 's. Compatibility of core properties such as fuel enrichment, geometry, control span, heat transfer and hydraulics must be assured in the context of reactor systems typical of these that will be operating in $1970-$ 1980 . 


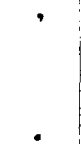

.

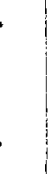

. 
TASK: FUEL IRRADIATIONS

TASK NUMBER: PRD-1

REFERENCE 189: Plutonium Utilization Program

Plutonium Recycle Demonstration

SCOPE: Perform irradiation proof tests of production-run EBWR $\mathrm{UO}_{2}-\mathrm{PuO}_{2}$ fue 1 $\overline{\text { rods, }}$ as well as capsules, to demonstrate their capability to operate satisfactorily in EBWR. Conduct surveillance of fuel rods irradiated in EBWR. Additional irradiation data will be obtained from vibrationally-compacted, pneumaticallyimpacted $\mathrm{UO}_{2}-\mathrm{PuO}_{2}$ to supplement those resulting from tests conducted under the Fuels Development portion of the Plutonium Utilization Program.

OBJECTIVE AND JUSTIFICATION: A major objective of this task is to assure satisfactory performance of the $\mathrm{UO}_{2}-\mathrm{PuO}_{2}$ fuel rods fabricated for EBWR by BNW.

More than 2000 vibrational1y-compacted $\mathrm{UO}_{2}$ (depleted)-1.5 wt\% $\mathrm{PuO} 2$ rods were prepared for cooperative ANL-BNW P1utonium Recycle Demonstration Experiment in the Experimental Boiling Water Reactor (EBWR). The purpose of the Demonstration Experiment is to obtain useful information for the utilization of plutonium as a fuel in light water, thermal systems - either an all-thermal plutonium recycle system or as a thermal part of a mixed fast-thermal reactor complex.

Information about the irradiation performance of prototype fuel rods is needed prior to and during the irradiation of the full-core loading in EBWR in order to verify the fuel rod design and physics and heat transfer calculational models and to provide lead time, in terms of burnup, in the event that unanticipated problems arise.

Irradiation tests are being conducted by BNW to obtain information on fission gas release, fuel sintering, plutonium and/or fission product migration, and springpellet-fuel compatibility.

Fifty-eight ful1-size rods are being or have been irradiated and four to six additional rods are scheduled for irradiation. Included is the $21-$ rod bundle to continue irradiation in a PRTR fringe position. Goal burnup for the bunde is $\geq 11,000 \mathrm{MWd} / \mathrm{MT}$. The maximum goal burnup on the remainder of the 58 rods is $27,500 \mathrm{MWd} / \mathrm{MT}$.

Thirty-three of 36 capsules have been discharged and the remaining 3 will complete their irradiation in FY-1968. Maximum goal burnup is $27,500 \mathrm{MWd} / \mathrm{MT}$. 
.

.

. 
REFERENCE 189: Plutonium Utilization Program Plutonium Recycle Demonstration (EBWR)

SCOPE: The EBWR core will be loaded with a plutonium fuel zone surrounded with uranium fuel elements which will be used as driver elements. Several rods will be included in the plutonium zone to obtain burnup information from special fuel compositions.

A series of tests is being conducted during the initial loading of the EBWR in order to measure the reactivity worth of fuel rods, safety rods, voids and boric acid in the moderator.

At various stages of burnup, the series of tests performed during the initial loading will be repeated. Also, at these stages a series of rods from the plutonium zone will be removed and returned to Battelle-Northwest for reactivity measurements in the Plutonium Recycle Critical Facility and subsequently analyzed for plutonium concentration, isotopic composition, and to obtain other data which will describe the burnup characteristics. Information obtained during the experiment will be used to assess the accuracy of the calculational methods and identify areas of uncertainty in the computations.

OBJECTIVE AND JUSTIFICATION: This experiment will demonstrate the utilization of plutonium in an $\mathrm{H}_{2} \mathrm{O}$ moderated power reactor of the BWR type. Computational techniques have been applied to critical experiments and burnup experiments with relatively good results. However, calculations concerning the multiplication constant of a core as a function of exposure and the exposure limit of reactivity have not been evaluated since no data from unperturbed loadings are available. These data are important since effects of uncertainties in physics variables can have a drastic effect on fuel cycle costs by causing uncertainties in exposure characteristics of reactivity.

Another experiment to demonstrate the utilization of plutonium in the Saxton Reactor, an $\mathrm{H}_{2} \mathrm{O}$ moderated power reactor of the PWR type, is also important for our analyses. Although both the EBWR and Saxton experiments are being conducted in light water moderator, there are major differences between the two which make them complementary for evaluating calculational methods as well as demonstrate the reliability of the plutonium fuel. Some of the more important differences occur because of the large difference in $\mathrm{PuO}_{2}$ concentration, the greater flexibility for more extensive experimentation in the EBWR experiment (the Saxton experiment has constraints on it because of other plant commitments), and the irradiation of special rods in the EBWR. 


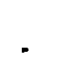


REFERENCE 189: Plutonium Utilization Program

Industrial Assistance

SCOPE: Procure, test, and evaluate fuel rods and/or elements designed and fabricated by commercial firms having interest in the thermal recycle of plutonium. In addition to two fuel elements to be irradiated in the PRTR core, an additional 50 individual rods of various plutonium enrichments will be irradiated in the core and the FERTF. Transient tests of irradiated and nonirradiated commercially procured rods will be performed in TREAT Reactor.

OBJECTIVE AND JUSTIFICATION: The major objective of this program is to investigate the irradiation behavior of commercially designed and fabricated pelleted $\mathrm{UO}_{2}$ $\mathrm{PuO}_{2}$ fuel rods, particularly in comparison with vibrationally-compacted $\mathrm{UO}_{2}-\mathrm{PuO}_{2}$ fuel rods designed and fabricated by BNW. The bulk of the justification for this program resides in the desire to make the Plutonium Utilization Program more directly industry-oriented.

The fuel development portion of the Plutonium Utilization Program has emphasized preparation, fabrication, irradiation, and evaluation of packed-particle fuel elements. Fuel elements fabricated by vibrational-compaction of fuel prepared by pneumatic-impaction have been irradiated extensively in the PRTR and in other test reactors employed under the Plutonium Utilization Program. Existing commercial power reactors, however, normally employ pelleted-UO 2 rather than packedpowder $\mathrm{UO}_{2}$ or $\mathrm{UO}_{2}-\mathrm{PuO}_{2}$ fuel.

In January, 1966, a delegation from BNW visited several industrial organizations interested in the Plutonium Utilization Program. The result of these meetings and discussions was a set of suggestions from the industrial participants for significant additions and/or changes to the Plutonium Utilization Program which would be of direct and vital interest to the commercial power reactor industry. These suggestions were generally in agreement with those made by BNW. Inclusion of $\mathrm{UO}_{2}-\mathrm{PuO}_{2}$ fuel elements incorporating pelleted fuel in the Batch Core was agreed to be important.

It is important to procure fuel elements which have been designed and fabricated by commercial power reactor developers. The fuel elements will be tested in the core of the PRTR in the same environments as the packed-powder fuel elements. They will be irradiated at the same power generation and to the same goal burnup as the packed-powder fuel elements. It is imperative, therefore, that the pelleted-fuel elements be representative of the best commercial designs. 


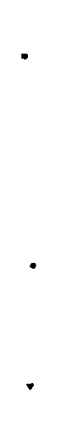


TASK: WATER GAP AND CONTROL ROD MEASUREMENTS

TASK NUMBER IA- 2

REFERENCE 189: Plutonium Utilization Program

Industrial Assistance

SCOPE: Power peaking about a single central lattice position or a row of lattice positions from which fuel has been removed will be measured by gamma scanning fuel rods. Reactivity measurements of various control materials of interest to industry will also be conducted.

OBJECTIVE AND JUSTIFICATION: The fuel rod lattice of a power reactor contains regions with additional water, structural, and control material within and between fuel assemblies. Excess moderation in these regions can result in power peaking in adjacent fuel rods. It is important to evaluate the ability of calculational methods to reproduce this flux peaking and control worth. 

TASK: POWER SHARING EXPERIMENTS

TASK NUMBER: IA-3

REFERENCE 189: Plutonium Utilization Program

Industrial Assistance

SCOPE: Experiments will be conducted to measure power sharing between zones of fuel elements containing different $\mathrm{Pu} 240$ concentrations and between zones of plutonium and uranium fuels using a fuel rod gamma scanner. The former experiments will be conducted at Pacific Northwest Laboratory and the latter at Westinghouse Reactor Evaluation Center. To accomplish this, interchange will be necessary between the two laboratories.

OBJECTIVE AND JUSTIFICATION: The first use of plutonium in commercial reactors is expected to be in zoned loadings of different fuel or different burnup characteristics. Measurements of power sharing between the zones, power peaking at the interface, and flux distributions are necessary to properly evaluate analytical procedures used in nuclear design of water moderated power reactors. 



\author{
REFERENCE 189: Plutonium Utilization Program \\ Industrial Assistance
}

SCOPE: Experiments will be conducted with boron in the moderator to determine the reactivity worth of the absorber and to reduce the neutron leakage from the cores.

OBJECTIVE AND JUSTIFICATION: The reactivity worth of the boron will be compared to experiments where the poison is lumped in several different arrays of poison rods. The results will be used to evaluate calculational techniques and to obtain information about the use of boron as a chemical shim. Recent information indicates that some of the problems in calculating critical masses of plutonium systems occurs because of incorrect calculations of neutron leakage. Experiments with boron in the moderator would reduce the leakage and help separate this effect from others. 


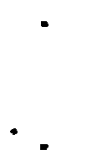


TASK: MEASUREMENTS WITH 4 wt: $\mathrm{PuO}_{2}-\mathrm{UO}_{2}$ FUEL

TASK NUMBER: IA - 5

REFERENCE 189: P1utonium Utilization Program

Industrial Assistance

SCOPE: Experiments to measure critical masses, bucklings, reflector savings and reactivity coefficients of fuel containing 4 wt: $\mathrm{PuO}_{2}-\mathrm{UO} \mathrm{O}_{2}$ will be conducted.

The experiments will cover a range of moderator to fuel ratios of interest to

PWR and BWR. Experimental techniques in use at various laboratories for uranium and plutonium systems will also be compared.

OBJECTIVE AND JUSTIFICATION: The concentration of $\mathrm{PuO}_{2}^{-U O}$ best suited for commercial reactors is expected to be between the range of data available now ( 2 and $6.6 \mathrm{wt} \%)$. The temperature and void coefficient of reactivity for the 2 and 6.6 wt: $\mathrm{PuO}_{2}-\mathrm{UO}_{2}$ are expected to be enough different to require measurements with an intermediate concentration. This fuel will allow investigation of the effects of approximations in calculational models at a $\mathrm{PuO}_{2}$ concentration that is predicted to be of real importance to future power reactor plutonium utilization. 


\author{
REFERENCE 189: Plutonium Utilization Program \\ Reactor Physics
}

SCOPE: Subcritical and critical experiments will continue in zero power reactors with emphasis on the effects of various $\mathrm{Pu}^{2} 40$ concentrations and on the detailed properties of the loadings without irradiation. Loading studies of $2 \mathrm{wt} \% \mathrm{PuO} 2-$ $\mathrm{UO}_{2}$ fuel elements containing 8,16 , or 24 wt: $\mathrm{Pu} 240$ and moderated with $\mathrm{H}_{2} \mathrm{O}$ will continue. Studies of the detailed properties of the loadings such as reaction rates, reactivity coefficients and kinetics will be continued for PuAl and puor$\mathrm{UO}_{2}$ fuels moderated with $\mathrm{H}_{2} \mathrm{O}$ in order to evaluate calculations of properties of plutonium systems other than their multiplication. The experiments will help locate the quantities which are causing major uncertainties in the calculations. In addition, some experiments should be repeated to confirm the accuracy of the results already obtained since they are to become a standard set of results for checking calculations at other laboratories.

Single region subcritical borated experiments will be conducted with selected

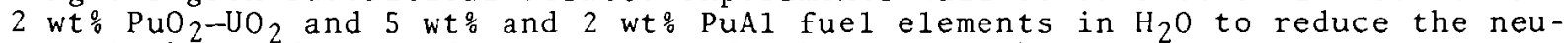
tron leakage effects of small cores (Task IA-4 also).

Single region unborated experiments will be conducted with 5 wt: and 2 wt: PuAl fuel elements in $\mathrm{H}_{2} \mathrm{O}$ as a check on experimental accuracy and as base measurements for experiments containing boron in the moderator.

Critical experiments will be conducted to determine (a) buckling (power and flux); (b) central water hole worth, control rod $\left(\mathrm{HfO}_{2}\right.$ and $\left.\mathrm{B}\right)$ worth measurements and multiple configurations; (c) void coefficients; (d) moderator level coefficients; (e) temperature coefficients; (f) cell fluxes; (g) kinetics parameters; (h) substitution reactivities; (i) power distributions - sharing of zoned cores, water hole and slot peaking (Task IA-2 and IA-3 also); (j) others of industrial concern if requested - "aluminum" plate power peaking, control rod measurements with $\mathrm{Ag}-\mathrm{In}-\mathrm{Cd}$ or other elements, etc.

Studies involving lattice spacings of 0.85 and 0.75 in. are contemplated. The first spacing corresponds to a moderator-to-fuel volume ratio of 1.8 . This value is intermediate between that of a typical pressurized and boiling water reactor at zero power or a boiling water reactor with an $225 \%$ void fraction. The second spacing corresponds to a ratio of 1.15 or a ratio typical of a pressurized reactor or a boiling water reactor with an $250 \%$ void fraction. The loadings will be a 2 wt $\mathrm{PuO}_{2}-\mathrm{UO}_{2}$ moderated with $\mathrm{H}_{2} \mathrm{O}$.

Measurements of $k_{\infty}$ for mixed oxide fuel will be made with $\mathrm{H}_{2} \mathrm{O}$ moderator. These measurements will be made using the same fuels that have been used in the critical and subcritical lattice studies and will be an important adjunct to the theoryexperiment correlations. In addition, experiments with puAl fuel elements moderated with $\mathrm{H}_{2} \mathrm{O}$ will be conducted.

OBJECTIVE AND JUSTIFICATION: Experimental data which are a severe test of analyses methods and which allow computational techniques to be evaluated for a range of moderator to fuel ratios are required. 
REFERENCE 189: Plutonium Utilization Program

Reactor Physics

SCOPE: Emphasis will be placed on application of plutonium fuel in power reactors and its behavior as a function of irradiation. The relationship between plutonium production, plutonium depletion, uranium depletion, and energy generated in the core will be determined to permit a more accurate evaluation of the relationship between reactivity change and total energy generated and in turn allow more accurate determination of fuel cycle costs.

Controlled reactor physics experiments are to be conducted with a $\mathrm{D}_{2} \mathrm{O}$ moderated (HPDC-PRTR) and an $\mathrm{H}_{2} \mathrm{O}$ moderated (EBWR) power reactor to determine the 1 ifetime characteristics of $\mathrm{a}^{2} \mathrm{PuO}_{2}-\mathrm{UO}_{2}$ loading in these reactors. Experiments and correlations will be accomplished with the initial fuel loading and at various stages of exposure of the $\mathrm{PuO}_{2}-\mathrm{UO}_{2}$ fuel. (References BNWL-126, BNWL-221, BNWL-CC-391).

The reactivity effects of possible fission product and plutonium migration in fuel elements being operated in a molten condition will be studied. The Plutonium Recycle Critical Facility in conjunction with the FERTF in the PRTR will be used for this study.

Nondestructive and destructive burnup analysis of PuAl, $\mathrm{UO}_{2}$ and $\mathrm{PuO}_{2}-\mathrm{UO}_{2}$ fuel will be accomplished. Nondestructive analyses of the elements are accomplished using the Plutonium Recycle Critical Facility (PRCF) and gamma-ray scanners. A fuel element after irradiation in the test reactor is loaded into the PRCF by remote operations. The effect of the fuel element on the reactivity of the PRCF is measured as a function of exposure in the test reactor. Information about burnup along the length of a rod is obtained using movable gamma-ray counters and a single channel analyzer. Information about the characteristic gamma spectrum at a position along the rod is obtained using a multichannel analyzer. The destructive samplings involve chemical and isotopic analyses of the materials of interest as well as fission products such as Nd, Rh, and Cs. Using new improved least squares fitting techniques, cross section ratios are obtained from these data.

OBJECTIVES AND JUSTIFICATION: Measurements of material concentration and cross section changes as a function of irradiation are important since effects of uncertainties in these variables can have drastic effects on fuel cycle costs. Data for correlating analytical and experimental determinations of these changes are obtained from controlled irradiations in a test reactor and subsequent destructive sampling or nondestructive analyses of the elements. 
REFERENCE 189: Plutonium Utilization Program Reactor Physics

SCOPE: Calculational methods will be defined to point out areas of disagreement with experiment, areas where processes are not fully understood or areas where approximations are invalid. The work will be broad enough to include development of reactor theory in problem areas indicated from theory-experiment correlation. While new areas will undoubtedly be indicated by experiment, work in the following areas is planned. Processing codes will be developed and maintained, new data will be collected, and the quality of existing data will be improved for the BNW Master Library system. The format structure of the library will be altered to correspond to ENDF/B so that data generated under the recently proposed Brookhaven program by DRD\&T can be used by the system. Emphasis will be placed on treating the resonance region and improving the descriptions of the cross sections of the fissile and fertile isotopes. Theoretical methods for calculating cross sections where measurements are inaccurate or missing will be developed. Evolution of the system will continue in the treatment of inelastic scattering and anisotropic scattering. Considerable work has been done in measuring scattering of neutrons from various moderating materia1s. The results of this work will be translated into a form appropriate for reactor analysis work. In addition, it is expected that an improved model will result for the two most used moderating materials in recycle concepts--water and graphite. The effect on calculated results because of the improvements will be evaluated.

Investigations as indicated from theory-experiment correlation will continue to determine the appropriate circumstances requiring the use of integral transport methods, differential transport methods, and Monte Carlo methods. The appropriateness of synthesis methods versus full dimensional treatments will be investigated through variational techniques and comparison studies. Machine time for survey analyses will be reduced through the use of improved approximate methods. Operating experience with the RBU Monte Carlo Code will provide criteria for the next generation code at an appropriate time to make full use of the computing capabilities of the new computers that are now being developed.

Increased flexibility and ease in reactor analysis will result from the chaining of a variety of codes into a master analysis system. Group constants will be calculated from an HRG-Spectrum Chain, an HRG-THERMOS chain, or a HAMLET-THERMOS chain. An anlysis link will be included for one and two dimensional transport or diffusion analysis. Burnup analysis will be provided by ALCHEMY.

OBJECTIVE AND JUSTIFICATION: Physics design methods need to be developed to obtain the more detailed analytical techniques required for plutonium fueled systems because of the nuclear characteristics of the plutonium. The objective is to develop the necessary theoretical methods and corresponding computer programs to analyze reactors fueled by plutonium and to predict the burnup of fuel (reactivity as a function of time). In survey studies, studies to choose between. competing concepts, and finai design analysis, it is necessary to predict with confidence required fuel enrichments and required control capacity. Consequently development of accurate analysis methods applicable to plutonium fueled reactors is a major objective. The BNW Master Library serves as the basic source of cross section data for laboratory wide reactor analysis work and allows evaluation of calculational techniques by standardizing to one method of cross section representation with flexibility of comparing various cross section sets.

The nuclear characteristics of plutonium (the multiple fertile and fissile isotopes, the low lying resonances, and the variation of alpha with energy) requires a much more accurate description of the thermal neutron spectrum to calculate reactivity to the same accuracy as with uranium systems. To describe the neutron spectrum accurately requires an accurate description of the scattering law of the moderating material. 


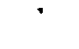

, 
REFERENCE 189: Plutonium Utilization Program

Reactor Physics

SCOPE: The data from subcritical, critical, and irradiation experiments will be used to evaluate the various analysis methods available. Data obtained at other laboratories also will be incorporated into the evaluations. The Yankee critical experiments and Saxton critical and irradiation experiments are examples of other data which are important for the evaluation of the methods.

Two dimensional and one dimensional methods will be used and Monte Carlo, transport, and diffusion theory techniques will be evaluated in order to determine the accuracies involved in the methods.

In addition to the results from experiments described the results from Saxton and Yankee experiments will be calculated to evaluate analysis methods. Reactivities, temperature coefficients, flux and power distributions will be correlated using the combination THERMOS-HRG-HFN. Kinetics, reactivity coefficients, power and flux will be calculated using Program $S_{n}$ in place of HFN. Reactivities, reactivity coefficients, and flux will be calculated using 4 -k ANGIE or other 2D code such as EXTERMINATOR. The two dimensional transport theory code DDK will be used to determine the importance of various representations of axial and radial leakage.

Monte Carlo techniques will be evaluated as well as using the technique to evaluate calculational assumptions. An infinite medium with atomic mass 20 and containing a constant scatter cross section and no capture will be completed. Results from Monte Carlo calculations will be compared to those obtained from HRG, TEMPEST, HFN, and THERMOS as a two way evaluation. The Monte Carlo calculation will be evaluated using results which come from identical or exact calculations with the other codes. The effect of assumptions of approximations will be evaluated with the Monte Carlo calculation. One important area is the influence of cell geometry on the results. This would probably be one using the results of solid rod and cluster experiments which have been conducted in the PCTR.

Reactivity values, isotopic concentrations, and kinetics information will be calculated for the PRTR-HPDC, EBWR, and Saxton results. One dimensional method will be evaluated using THERMOS-HRG-HFN or $S_{n}$ combinations and ALTHAEA.

Two dimensional methods employing Program ASSAULT will be evaluated using reactivity and reactivity coefficient measurements. Results of measurements of isotopic concentrations from Lx PuA1, Hx PuAl, mixed oxide, and EBWR special rods will be compared to results obtained from calculations using ALTFAEA and HAMMER-HFN or $S_{n}$ combinations. The high burnup data from the Lx PuAl results would be used to first determine whether HAMMER can handle high Pu240 results adequately. If this is the case then HAMMER would be used as a basic tool for calculating the $\mathrm{Hx}$ PuAl and Mixed Oxide results.

OBJECTIVE AND JUSTIFICATION: The reactor designer wants to know how complicated a model is needed to predict within a desired accuracy the properties of plutonium lattices. Design analysis methods will be evaluated for Pu-enriched $\mathrm{H}_{2} \mathrm{O}$ lattices and their adequacy for uranium enriched lattices will be demonstrated. A set of prescriptions will be obtained for analysis of the complex PWR and BWR systems to complement the more basic analytical methods which work for simple lattices. 


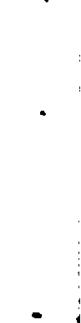

. 
TASK: PARTICLE SIZE EFFECTS

TASK NUMBER: $\quad$ P -5

REFERENCE 189: Plutonium Utilization Program

Reactor Physics

SCOPE: An experiment to study the effect of particle sizes of $\mathrm{PuO}_{2}$ in $\mathrm{UO}_{2}$ on reactivity will be conducted in the PCTR. Fuel rods are being designed so that most of the loading will be made up of fuel rods which are available from other experiments. The remainder of the loading will consist of rods made from material of a given particle size of $\mathrm{PuO}_{2}$. Fuel containing particle sizes in the range of 0 to 700 microns will be studied.

Experiments will also be conducted to measure reactivity effects and power distributions to simulate extreme lumping conditions such as lumping the $\mathrm{PuO}_{2}$ in the mixed oxide fuel element in a manner similar to the core of a pencil.

Another experiment to determine the reactivity effects of fuel diffusion properties and particle size changes with irradiation is being considered.

OBJECTIVE AND JUSTIFICATION: Fuel element development for plutonium recycle has led to fuels composed of the mixed oxides of plutonium and uranium. In these fuels the power generation occurs mainly because of the plutonium which occurs as particles in the UO2. Due to the self shielding properties of the particle, the reactivity of the fuel depends on the particle size. It is important to know the effect that the plutonium particle size has on the characteristics of the reactor system since the particle size can change during irradiation. Also, calculations indicate that improved nuclear characteristics may be accomplished by lumping the $\mathrm{PuO}_{2}$. An experimental program to measure the dependence of reactivity on particle size and theoretical program to develop the necessary analysis methods to calculate the effects is in progress. 


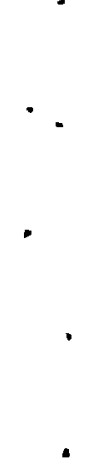


REFERENCE 189: Plutonium Utilization Program

Reactor Physics

SCOPE: This program can be considered as occurring in three phases: 1) Critical Experiments, 2) Power Experiments, and 3) Burnup Experiments. The critica1 experiments will be accomplished with 55 elements and will provide initial burnup conditions and tests of calculational methods. After the critical experiments with the 55 element core are completed other fuel elements and irradiation facilities will be loaded. Twelve elements of similar composition as the 55 elements and 13 others remaining from previous irradiation tests. The last five positions will be cooled with $\mathrm{D}_{2} \mathrm{O}$ and will be available if required for special tests.

The power experiments serve the dual purpose of characterizing the basic core data as well as providing operational and safeguards information. Important data to be obtained from these tests are the reactivity worth of equilibrium fission products (principally xenon and samarium), and information about the stability of the core.

Burnup experiments are scheduled after about every three months of full power operation and will require shutting the reactor down and repeating the critical and power tests but in lesser detail. At these times, a fuel rod from a cluster in the basic 55 element core will be destructively analyzed to determine its isotopic composition. This rod will be replaced by a rod of similar exposure from the region outside the 55 element core. This sequence of irradiating and testing will continue until fission product poisoning and fuel element burn-out prohibit further operation of the core without recharging fuel.

OBJECTIVE AND JUSTIFICATION: The PRTR Batch Core Experiment will make available reactor physics data obtained from an environment which is readily analyzable because of the simplicity of the reactor system as well as information about the irradiation characteristics of plutonium fuels. The experimental program is designed to give both the excess reactivity and fuel composition of the core as functions of time. Computational techniques have been applied to critical experiments and burnup experiments with relatively good results. However, calculations concerning the multiplication constant of a core as a function of exposure and the exposure limit of reactivity have not been evaluated since no data from unperturbed loadings are available. These data are important since effects of uncertainties in physics variables can have a drastic effect on fuel cycle costs by causing uncertainties in exposure characteristics of reactivity. 


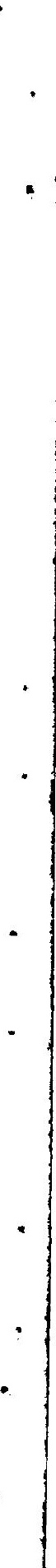


REFERENCE 189: Plutonium Utilization Program Cycle Analysis

SCOPE: Apply sufficient1y sophisticated computer codes, including the use of Transport. Theory and Monte Carlo methods, to accurately assess the economics of various novel applications of plutonium fuels.

These studies will include: evaluation of incentives for separating plutonium that grows into a fuel element from initial plutonium enrichment and for using lumped or "pencil" configuration fuels, evaluation of possibilities for combining fertile fuels so as to produce very flat reactivity characteristics or extreme fertility, and investigation of the advantages of using plutonium fuels in a reactor where the spectrum is adjusted by moderator displacement.

OBJECTIVE AND JUSTIFICATIONS: Out of preliminary cycle analyses, physics design analyses, and fuels development studies done under PUP have come some outstanding ideas for improved utilization of plutonium. The implementation of these ideas would require some changes in fuel geometry or changes in the reactor control system from those of present day reactor concepts. Such changes can be accommodated in the still developing designs of the next generation of thermal reactors.

Detailed and accurate cycle analyses will indicate the incentives for pursuing these ideas into the experimental stage.

Preliminary indication of incentives have been derived for the concepts described above.

- Plutonium values can be improved 10-20\% by separating the plutonium that grows into a fuel from that in the initial enrichment.

- Lumping of fuel will reduce the effective capture-to-fission ratio ( $\alpha$ ) for $\mathrm{Pu} 239$ by nearly $10 \%$. This has the effect of increasing the value of Pu239 and reducing the fuel cycle burnout cost. Fissile material lumping can be applied to any reactor but will be of particular interest in advanced BWR's and PWR's due to the possibility of matching the plutonium cross sections with the uranium cross sections for which the reactors were initially designed.

- By combining uranium, thorium, and plutonium isotopes it seems possible to produce fuels with relatively flat reactivity curves.

- In other combinations these same fissile isotopes may produce fuels of extreme fertility. Thus, a fuel of only 10-15\% fissile material density could be produced allowing the use of an inert matrix for improved heat transfer or restraint of swelling. This opens up possibilities for producing fuels of very high specific power and perhaps reducing the core size of power reactors to less than one-fifth of their current size.

- The neutron spectrum in a reactor can be altered by displacing moderator from the core. In the presence of fuels with considerable resonance structure, particularly plutonium, it is possible to significantly increase fuel burnup and the conversion ratio by mechanically displacing the moderator of the reactor. Preliminary indications are that this concept yields a very low cost fuel cycle for plutonium recycle in PWR's. 


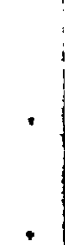




\section{DISTRIBUTION}

No. of

Copies

2

Argonne National Laboratory

R. Avery

R. E. Macherey

1 Atomic Energy Commission Toronto Technical Representative

D. G. Boyer

4 Atomic Energy Commission, Washington

Division of Reactor Development and Technology

A. Giambusso

R. M. Grube

M. Shaw

E. E. Sinclair

1 Atomic Energy Commission Limited

Chalk River, Canada

M. N. Hudson

1 Battelle Memorial Institute

D. L. Morrison

1 Combustion Engineering

W. P. Chernock

Division of Technical Information Extension

2 Douglas United Nuclear

C. D. Harrington

C. W. Kuh1man

2 Edison Electric Institute 750 Third Ave.,

New York, N. Y. 10017

H. A. Wagner, Chairman EEI Committee on Nuclear Fuels

2 Genera1 Electric Company, APED

R. B. Richards

E. L. Zebroski

4 Genera1 Electric Company, P1easanton

L. P. Bupp

J. G. Carver

E. A. Evans

A. B. Greninger
No. of

Copies

$1 \quad$ Nuclear Materials and Equipment Corporation

C. S. Caldwell

3 Richland Operations Office

L. R. Lucas

P. G. Holsted

C. L. Robinson

1 United Nuclear Corporation

C. Graves

4 Westinghouse Electric Corp.

R. J. Allio

H. Graves

W. H. Ray

J. H. Wright

$35 \quad$ Battelle-Northwest

F. W. Albaugh

J. W. Batch

S. H. Bush

J. J. Cadwe11

F. G. Daws on

D. R. de Halas

R. F. Dickerson

R. L. Dillon

E. A. Eschbach

S. L. Fawcett

J. R. Fishbaugher

J. C. Fox

H. Harty

R. E. Heineman

P. L. Hofmann

A. R. Keene

D. D. Lanning

W. R. Lewis

R. E. Nightingale

H. M. Parker

R. S. Pau 1

L. T. Pedersen

A. M. Platt

W. D. Richmond

W. E. Roake

L. C. Schmid

D. H. Stewart

E. E. Voiland

M. T. Walling

R. G. Wheeler

D. C. Worlton

Technical Information Files (2)

Technical Publications (2) 


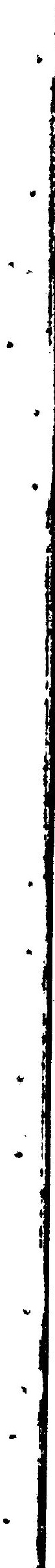

